\title{
Pulsative flushing as a strategy to prevent bacterial colonization of vascular access devices
}

This article was published in the following Dove Press journal:

Medical Devices: Evidence and Research

7 November 2014

Number of times this article has been viewed

\author{
Agnès Ferroni' \\ Florian Gaudin' \\ Gérard Guiffant ${ }^{2}$ \\ Patrice Flaud ${ }^{2}$ \\ Jean-Jacques Durussel ${ }^{2}$ \\ Philippe Descamps' \\ Patrick Berche' \\ Xavier Nassif ${ }^{\prime}$ \\ Jacques Merckx ${ }^{2}$
}

'Assistance Publique-Hôpitaux de Paris, Laboratory of Microbiology, University Teaching Hospital Necker-

Enfants Malades, ${ }^{2}$ University ParisDiderot, MSC-UMR, CNRS 7057,

Paris, France
Correspondence: Agnès Ferroni Laboratoire de Microbiologie, Hôpital Necker-Enfants Malades,

149 Rue de Sèvres, 750I5, Paris, France

Tel +33 | 4449496 I

Fax +33 । 44494960

Email agnes.ferroni@nck.aphp.fr

\begin{abstract}
Central venous device infections are associated with increased physical and psychological morbidity, mortality, length of stay, and costs. The aim of this study was to prove the efficacy of pulsatile flushing to prevent the bacterial colonization of vascular access devices. One hundred and forty four tests using 576 polyurethane short venous access catheters were performed. Four catheters per test were polluted with a fibronectin-serum albumin solution. Three were filled with a Staphylococcus aureus broth; one served as negative control. One contaminated catheter was not flushed (positive control), and two were flushed (10 mL.sec $\left.{ }^{-1}\right)$ with normal saline solution, either by ten successive boluses of $1 \mathrm{~mL}$ each or by one bolus of $10 \mathrm{~mL}$. Each catheter was cultivated. The $S$. aureus quantity observed after continuous flushing was significantly higher than that observed after pulsative flushing $(P<0.001)$. Unflushed catheters were 20.71 and 6.42 times more polluted than catheters flushed with the pulsative method or the continuous method, respectively. Pulsative flushing was at least twice as effective as continuous flushing in reducing the $S$. aureus count. Pulsative flushing is more effective than continuous flushing in reducing the endoluminal contamination. Pulsative flushing is a simple, effective, and inexpensive technique to reduce catheter bacterial colonization.
\end{abstract}

Keywords: peripheral or central venous devices, hydrodynamics, bacterial colonization prevention, pulsative flushing

\section{Introduction}

Intravascular catheters are the most frequently used medical devices in hospitals. However, they are associated with a life-threatening catheter-related bloodstream infection (CR-BSI), which is one of the main hospital-acquired infections as the incidence ranges from 0.1 to 11.3 per 1,000 catheter days. ${ }^{1-3}$ CR-BSI is associated with morbidity, psychological suffering, mortality, and additional medical cost. The high rate of these infections is explained by the fact that bacterial colonization of indwelling catheters is frequently reported: $25 \%$ of indwelling intravenous catheters become colonized with bacteria. ${ }^{4,5}$

To reduce CR-BSI, behavioral interventions for health care workers can be conducted, but the impact of such interventions varies greatly, ranging from nonsignificant decreases to significant reductions of CR-BSIs. ${ }^{6,7}$ Currently in France, it is recommended that implanted ports be flushed with $10 \mathrm{~mL}$ of sterile saline solution by pulsative flushing in order to prevent obstruction, which is a potential source of infection. ${ }^{8}$ In a previous study, the effectiveness of pulsative flushing of catheters versus continuous flushing was demonstrated to remove a protein layer present on the endoluminal wall of the catheter. ${ }^{9}$ The question that arises is whether this flushing policy could be an 
effective means to reduce the colonization of the endoluminal space. The purpose of the present study was to assess, in controlled flow conditions, the bacteriological effectiveness of pulsative flushing on catheters polluted by the same protein solution supplemented with a Staphylococcus aureus broth of known concentration. The aim was to demonstrate the advantage of using a pulsative flushing technique versus a continuous flushing technique in preventing the accumulation of bacteria on the catheter endoluminal wall, before the biofilm formation. The bacteriological efficacy of this method was measured by the amount of $S$. aureus collected after flushing the lumen of tested catheters.

\section{Materials and methods}

The intravenous catheters used were polyurethane catheters BD Insyte ${ }^{\mathrm{TM}}$ (Becton Dickinson). They allow a flow of $330 \mathrm{~mL} / \mathrm{min}$ and are $45 \mathrm{~mm}$ long. The outer and inner diameters are $2.1 \mathrm{~mm}$ and $1.74 \mathrm{~mm}$, respectively. The internal surface is $2.46 \mathrm{~cm}^{2}$ and the internal volume is $0.142 \pm 0.003 \mathrm{~mL}$.

As per the protocol described by Pellenc et al, ${ }^{10}$ two protein solutions were used: $50 \mathrm{mg} / \mathrm{mL}$ bovine serum albumin (Sigma-Aldrich, France) and $5 \mu \mathrm{g} / \mathrm{mL}$ fibronectin (FN) (SigmaAldrich). The bacterial strain used in the study was the $S$. aureus reference strain ATCC 2523. Preliminary tests allowed us to select a concentration of $10^{5}$ colony forming units $(\mathrm{CFU}) / \mathrm{mL}$ of $S$. aureus to obtain a clinically significant inoculum.

The experiment was designed as a set of 144 tests. A total of 576 catheters were used (four catheters per test). Each test lasted 4 days. At day 1, the four catheters were flushed with a $0.1 \%$ solution of sodium dodecylsulfate in pure water then filled with the FN solution, incubated at $35^{\circ} \mathrm{C}$ for 2 hours, and emptied by gravity. In a second phase, the catheters were filled with the bovine serum albumin solution, incubated at $35^{\circ} \mathrm{C}$ for 24 hours and emptied by gravity. Three catheters were filled with the $S$. aureus solution. The fourth catheter was used as a negative control (no bacterial pollution, no flushing). The four catheters were then incubated at $35^{\circ} \mathrm{C}$ for 24 hours. The three contaminated catheters were emptied. Of these three catheters, one served as a contamination positive control and was not flushed. The two other test catheters were flushed: one by ten successive bolus of $1 \mathrm{~mL}$ normal saline solution (pulsative flushing), the other by a single bolus of $10 \mathrm{~mL}$ (continuous flushing). The steps are summarized in Figure 1.

Flushing was performed with a syringe containing physiological saline $0.9 \%$ (Becton Dickinson). An adapted pump allowing flow rates control was provided by the University Paris-Diderot.

According to Royon et al, ${ }^{11}$ a flushing injection time of $\tau_{\mathrm{f}}=0.1$ second and a delay of $\tau_{\mathrm{i}}=0.9$ seconds have been defined. The amount of $S$. aureus collected from the lumen of the tested devices was measured by the following bacteriological method: each catheter was collected in a sterile container, in which $1 \mathrm{~mL}$ saline buffer was added, the residual liquid in the catheter was emptied by a syringe, the container was vortexed 30 seconds, and $100 \mu \mathrm{L}$ of the solution was sowed on blood agar medium. After 24 hours of incubation at $35^{\circ} \mathrm{C}$, the colonies were counted in $\mathrm{CFU} / \mathrm{mL}$.

\section{Statistical analysis}

A statistical analysis was performed using $\mathrm{R}$ (language and environment for Statistical Computing, R Foundation for Statistical Computing, Vienna, Austria). The Shapiro normality test showed that the distributions of the contamination (CFU/mL) for the different treatments were not normal. A nonparametric test (one-sided Wilcoxon rank sum test) was performed. To compare the pulsative and continuous count distributions; $P$-values of $\leq 0.05$ were considered significant.

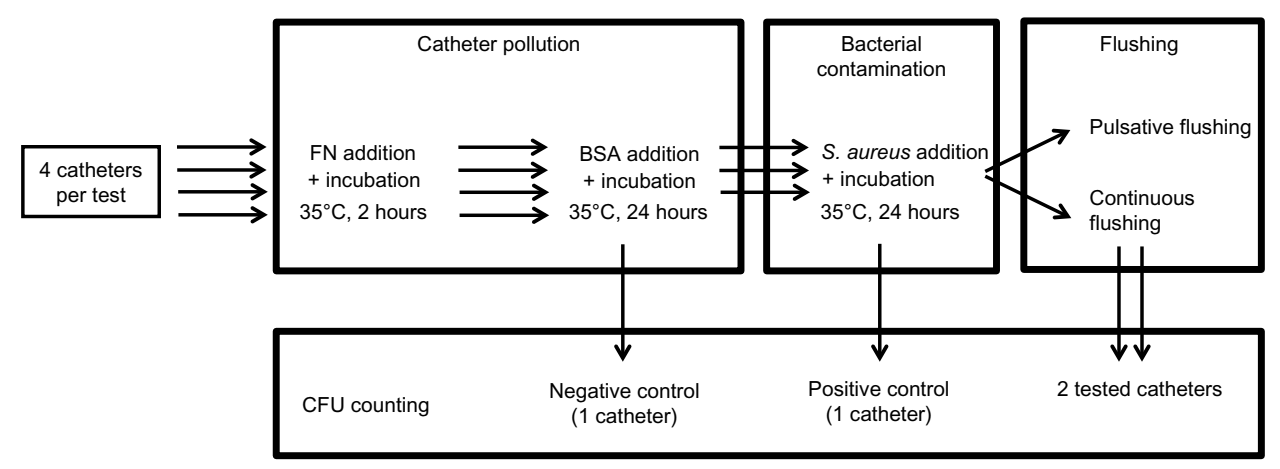

Figure I Design of the protocol.

Abbreviations: FN, fibronectin; BSA, bovine serum albumin; CFU, colony forming units; S. aureus, Staphylococcus aureus. 
Median counts were computed for each technique. In addition, a ratio of these medians and corresponding 95\% confidence intervals of these estimates were computed via bootstrap. A ratio of the $95 \%$ confidence intervals of the pulsative and continuous median counts was computed to compare the reproducibility of the two techniques.

\section{Results}

During the study, 576 catheters were used. The dispersion of the contamination among the four different catheters is shown in Figure 2. Regarding the 144 tests performed, the overall comparison of the continuous and pulsative flushing counts shows that the counts observed after continuous flushing are significantly higher than those observed after pulsative flushing $(P<0.001)$. Ten successive boluses of $1 \mathrm{~mL}$ are significantly more efficient than a single bolus of $10 \mathrm{~mL}$. A summary of the catheter contamination results is provided in Table 1. The overall median (continuous flushing)/median (pulsative flushing) rate is 3.26 and its bootstrapped $95 \%$ confidence interval is $2.24-4.61$. This means that pulsative flushing is at least twice as effective as continuous flushing in reducing the number of $\mathrm{CFU} / \mathrm{mL}$.

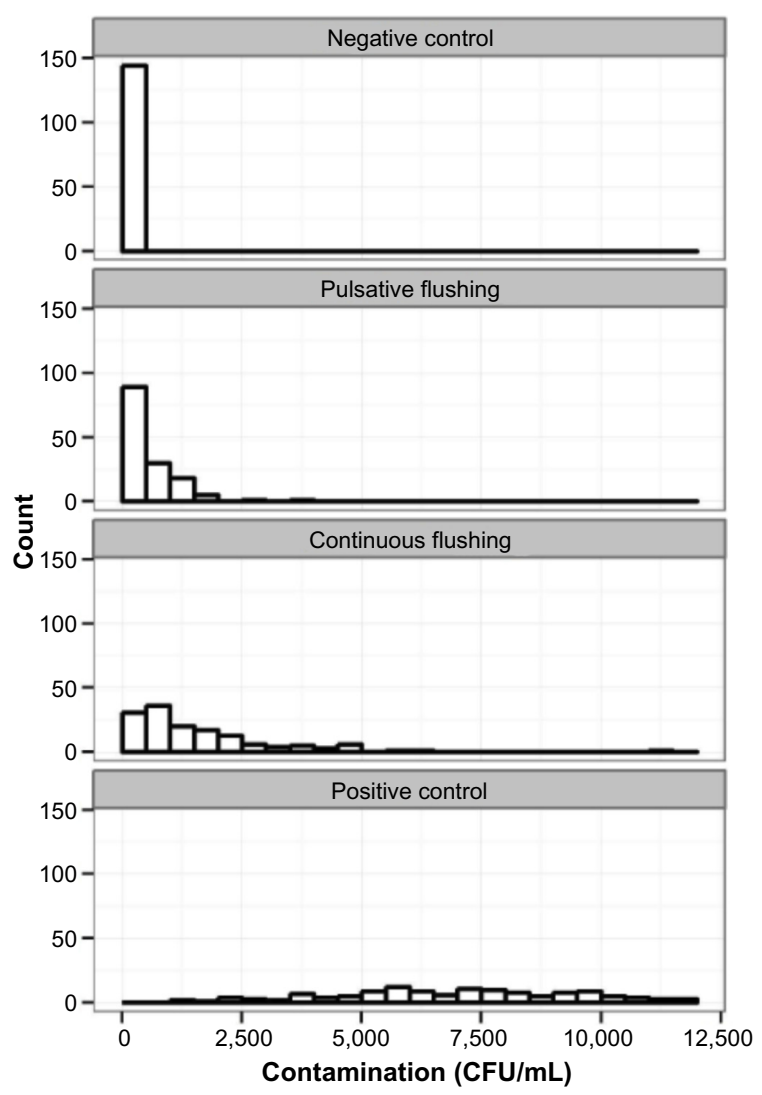

Figure 2 Histogram of contamination per flushing treatment. Abbreviation: $\mathrm{CFU}$, colony forming units.
Table I Results of the I 44 cultivated catheters in colony forming units (CFU)/mL

\begin{tabular}{lllll}
\hline Catheter & $\mathbf{n}$ & Mean & Median & Range \\
\hline Negative control & $\mathrm{I} 44$ & 0.07 & 0 & $0-10$ \\
Positive control & $\mathrm{I} 44$ & $7,633.26$ & 7,400 & $\mathrm{I}, \mathrm{I} 70-25, \mathrm{I} 20$ \\
Continuous flushing & $\mathrm{I} 44$ & $\mathrm{I}, 615.97$ & $\mathrm{I}, \mathrm{I40}$ & $30-\mathrm{II}, 080$ \\
Pulsed flushing & $\mathrm{I} 44$ & $524.3 \mathrm{I}$ & 350 & $0-3,640$ \\
\hline
\end{tabular}

The ratio of the width of the median (continuous flushing)/median (pulsative flushing) confidence intervals is equal to 3.33 , meaning that the reproducibility observed with pulsative flushing is 3.33 times that observed with continuous flushing. The median count comparison shows that unflushed catheters were 20.71 times more polluted than catheters flushed with a pulsative method and 6.42 times more polluted than catheters flushed with continuous method.

\section{Discussion}

This study demonstrated experimentally that the amount of S. aureus recovered after pulsative flushing is greater than that recovered after continuous flushing. Although we did not have the opportunity to observe the intraluminal surface of catheters by electron microscopy, these results allow for the assumption that the elimination of $S$. aureus from this surface would be more effective after pulsative flushing compared with continuous flushing. No similar studies have been found in literature. Although peripheral catheters were used in this work, the results can be extrapolated to all catheters because the flushing efficacy depends on the technique used. ${ }^{10}$ It is a physical hydrodynamics characteristic that can be applied to all cannula.

We noticed that even if there is a clear difference between the two methods in the rate of contamination, the number of colonies varies greatly from one test to another within a single method, while the same $S$. aureus inoculum was used for all tests. The variability of these results could be explained by the fact that bacteria are living organisms whose metabolism and ability of adhesion may undergo some variations over time.

The genus Staphylococcus was chosen in this work because staphylococci are known to bind to intravascular catheters. S. aureus and Staphylococcus epidermidis are the most frequently species recovered in CR-BSI as they are major skin contaminant species., ${ }^{5-14}$ The species $S$. aureus was chosen in order to easily identify the inoculated bacteria from any external catheter contamination by commensal bacteria. 
Staphylococcal infections associated with indwelling medical devices involve the formation of a biofilm. ${ }^{15}$ These infections are chronic or relapsing and often induce removal of the infected medical device. Catheter removal is mandatory in case of CR-BSI due to $S$. aureus, because of its significant morbidity. ${ }^{1}$

Staphylococcal adherence to either a biotic or abiotic surface is the critical first event in the establishment of an infection. Bacterial cells adhere to the endoluminal matrix, which is made of serum proteins. FN and albumin were selected in this work because both are physiological blood proteins. Furthermore, FN easily and strongly adheres to biomaterials and to blood products and also promotes the adhesion of albumin and other proteins. ${ }^{10,16,17}$

Adherence of $S$. aureus appears to be dependent on the presence of host-tissue ligands, including FN and collagen. ${ }^{18}$ FN in plasma contains a strong binding site for $S$. aureus as well as marked affinity for inert plastics and, therefore, may provide a substrate for bacterial adherence to indwelling catheters. ${ }^{19-21} \mathrm{FN}$ proteins reproduce the adherence of staphylococci in vitro in presence of blood. Russel et al showed that FN significantly increased in vitro the adherence of $S$. aureus to polyvinyl-chloride and polyurethane catheters. ${ }^{19}$ Vaudaux et al showed that in the presence of serum, the level of staphylococcal adherence to explanted coverslips was 20 times higher than that of adherence to unimplanted coverslips. ${ }^{22}$ Adherence to explanted coverslips was caused by FN deposits on the foreign body surface and was inhibited in a dose-related fashion by specific antibodies to FN. ${ }^{22}$ Compared with noninserted catheters, which allowed only minimal adherence, previously inserted catheters promoted significant adherence of staphylococcal isolates from patients with intravenous device infection. ${ }^{23}$

This high ability of staphylococcal adherence requires the use of an effective method such as pulsative flushing to detach the bacteria before the irreversible formation of a biofilm. The elimination of biofilms on intravascular catheters is indeed a challenge for practitioners. The difficulty of eradicating biofilms encourages eliminating quickly the bacterial colonization from the endoluminal surface of the catheter, before the first steps of biofilm formation (attachment of planktonic cells and formation of microcolonies). In addition, if the flushing removes the germs possibly present before the stage of irreversible attachment during the formation of the biofilm, the risk of dispersing a large inoculum of bacteria into the bloodstream, which may be a risk factor for bacteremia, is then reduced.
In the literature, few studies on flushing hydrodynamics have been provided, ${ }^{84-27}$ and, until the present study, there was no proof of the antimicrobial efficacy of the pulsative flushing technique for catheters. In a previous study, using the same method as the one applied in this work, Guiffant et $\mathrm{al}^{9}$ concluded that hydrodynamics is critical for removing proteins from the endoluminal wall of a catheter and that the adjunction of an intermittent component in the flow increases this effect.

According to Donlan, ${ }^{28-30}$ bacterial cells behave as particles in a liquid, and the rate of settling and deposition on a submerged surface will depend largely on the characteristics of the velocity distribution of the liquid in the vicinity of the submerged surfaces. Under very low linear velocities, the cells can easily traverse the hydrodynamic boundary layer. As the velocity increases, the protein and microorganism deposits decrease. High linear velocities induce substantial shear forces, resulting in the detachment of these cells. The flushing of venous catheters is a complex process, where convection and diffusion are coupled with chemical interactions associated with protein adhesion and disadhesion. ${ }^{9}$ Moreover, the flushing efficacy could be enhanced by heating up the flushing solution to body temperature, as shown by Guiffant et al. ${ }^{31}$

In terms of flushing, it is essential to consider bacterial adhesion and colonization. Royon et al explained that the mass balance of proteins attached to the catheter wall has to be considered: over time, the chemical interactions between proteins increase, inducing inefficient flushing. ${ }^{11}$ By extension, this would be the same process with microorganisms, meaning that in clinical practice, flushing should be repeated frequently.

Among all the CR-BSI prevention strategies related to peripheral and central catheters, pulsative flushing is a simple, effective, and inexpensive technique, associated with good practice. Pulsative flushing appears to be efficient in reducing catheter bacterial colonization to prevent bacteremia. Further studies would be necessary to confirm in vivo the results of this in vitro study.

\section{Acknowledgment}

This work was supported by Becton Dickinson, BP 4, 38801 Le Pont-De-Claix Cedex, France.

\section{Disclosure}

The authors report no conflicts of interest in this work. 


\section{References}

1. O'Grady NP, Alexander M, Dellinger EP, et al. Guidelines for the prevention of intravascular catheter-related infection. The Hospital Infection Control Practices Advisory Committee, Center for Disease Control and Prevention, US Pediatrics. 2002;110:e51.

2. Coello R, Charlett A, Ward V, et al. Device-related sources of baacteraemia in English hospitals - opportunities for prevention of hospital-acquired bacteraemia. J Hosp Infect. 2003;53(1):46-57.

3. Percival SL, Kite P. Intravascular catheters and biofilm control. J Vasc Access. 2007;8:69-80

4. Adams JM, Speer ME, Rudolph A. Bacterial colonization of radial artery catheters. Pediatrics.1980;65:94-97.

5. Fletcher S. Catheter-related bloodstream infection. Contin Educ Anaesth Crit Care Pain. 2005;5:49-51.

6. Coopersmith CM, Zack JE, Ward MR, et al. The impact of bedside behavior on catheter-related bacteremia in the intensive care unit. Arch Surg. 2004;139:131-136.

7. Jeffries HE, Mason W, Brewer M, et al. Prevention of central venous catheter-associated bloodstream infections in pediatric intensive care units: a performance improvement collaborative. Infect Control Hosp Epidemiol. 2009;30:645-651.

8. Société Française d'Hygiène Hospitalière. Prévention des infections associées aux chambres à cathéter implantables pour accès veineux. Hygiènes. 2012:XX;1.

9. Guiffant G, Durussel JJ, Merckx J, Flaud P, Vigier JP, Mousset P. Flushing of intravascular access devices (IVADs) - efficacy of pulsed and continuous infusions. J Vasc Access. 2012;13(1):75-77.

10. Pellenc D, Berry H, Gallet $\mathrm{O}$. Adsorption-induced fibronectin aggregation and fibrillogenesis. J Colloid Interface Sci. 2006;298(1): 132-144.

11. Royon L, Durussel JJ, Merckx J, Flaud P, Vigier JP, Guiffant G. The fouling and cleaning of venous catheters: a possible optimization of the process using intermittent flushing. Chem Eng Res Des. 2012;90(6): 803-807.

12. Wadström T. Molecular aspects on pathogenesis of wound and foreign body infections due to staphylococci. Zentralbl Bakteriol Mikrobiol Hyg A. 1987;266(1-2):191-211.

13. Walz JM, Memtsoudis SG, Heard SO. Prevention of central venous catheter bloodstream Infections. J Intensive Care Med. 2010;25(3): $131-138$.

14. [No authors listed]. Managing bloodstream infections associated with intravascular catheters. Drug Ther Bull. 2001;39:75-80.

15. Hall-Stoodley L, Stoodley P. Evolving concepts in biofilm infections. Cell Microbiol. 2009;11(7):1034-1043.
16. Horbett TA. The role of adsorbed proteins in animal cell adhesion. Colloids Surf B Biointerfaces. 1994;2(1-3):225-240.

17. Potts JR, Campbell ID. Fibronectin structure and assembly. Curr Opin Cell Biol. 1994;6(5):648-665.

18. Darouiche RO. Device-associated infections: a macroproblem that starts with microadherence. Clin Infect Dis. 2001;33:1567-1572.

19. Russel PB, Kline J, Yoder MC, Polin RA. Staphylococcal adherence to polyvinyl chloride and heparin-bonded polyurethane catheters is species dependent and enhanced by fibronectin. J Clin Microbiol. 1987;25(6):1083-1087.

20. Nemet B, Zagar Z. Fibronectin concentrations in catheter sepsis. Clin Microbiol Infect. 2000;6:3:121-124.

21. Vaudaux P, Pittet D, Haeberli A, et al. Fibronectin is more active than fibrin or fibrinogen in promoting Staphylococcus aureus adherence to inserted intravascular catheters. J Infect Dis. 1993;167(3): 633-641.

22. Vaudaux P, Waldvogel FA, Morgenthaler JJ, Nydegger UE. Adsorption of fibronectin on polymethylmethacrylate and promotion of Staphylococcus aureus adherence. Infect Immun. 1984;45:62-73.

23. Vaudaux P, Lew DP, Waldvogel FA. Host factors predisposing to foreign body infections. In: Bisno AL, Waldvogel FA, editors. Infections Associated With Indwelling Medical Devices. Washington, DC: American Society for Microbiology; 1989:3-26.

24. Hadaway L. Flushing vascular access catheters: Risks for infections transmission. Infection Control Resource. 2007;4(2):1-8.

25. Hadaway L. Technology of flushing vascular access devices. J Infus Nurs. 2006;29:137-145.

26. Hadaway L. Flushing to reduce catheter occlusions. Nursing. 2000;30:74.

27. Bertoglio S, Rezzo R, Merlo FD, et al. Pre-filled normal saline syringes to reduce totally implantable venous access device-associated bloodstream infection: a single institution pilot study. $J$ Hospital Infect. 2013;84:85-88.

28. Donlan RM. Biofilms and device-associated infections. Emerg Infect Dis. 2001;7:277-281.

29. Donlan RM. Biofilms: microbial life on surfaces. Emerg Infect Dis. 2002;8(9):881-890.

30. Donlan RM. Biofilm elimination on intravascular catheters: important considerations for the infectious diseases practitioner. Clin Infect Dis. 2011;52(8):1038-1045.

31. Guiffant G, Durussel JJ, Flaud P, Royon L, Marcy PY, Merckx J. Power port contrast medium flushing and trapping: impact of temperature, an in vitro experimental study. Med Devices (Auckl). 2013;6:133-140.
Medical Devices: Evidence and Research

\section{Publish your work in this journal}

Medical Devices: Evidence and Research is an international, peerreviewed, open access journal that focuses on the evidence, technology, research, and expert opinion supporting the use and application of medical devices in the diagnosis, treatment and management of clinical conditions and physiological processes. The identification of novel

\section{Dovepress}

devices and optimal use of existing devices which will lead to improved clinical outcomes and more effective patient management and safety is a key feature. The manuscript management system is completely online and includes a quick and fair peer-review system. Visit http://www. dovepress.com/testimonials.php to read real quotes from authors. 